\title{
High and Low Temperature Properties of FT-Paraffin-Modified Bitumen
}

\author{
Hassan Fazaeli, ${ }^{1}$ Hamid Behbahani, ${ }^{1}$ Amir Ali Amini, ${ }^{1}$ \\ Jafar Rahmani, ${ }^{2}$ and Golazin Yadollahi ${ }^{3}$ \\ ${ }^{1}$ School of Civil Engineering, Iran University of Science and Technology, Narmak, Tehran 1684613114, Iran \\ ${ }^{2}$ Department of Supervision and Control, Iran Ministry of Road and Transportation, North Kargar St., Tehran 1416753941, Iran \\ ${ }^{3}$ Technical \& Soil Mechanics Lab, Iran Ministry of Road \& Transportation, North Kargar St., Tehran 1439956111, Iran
}

Correspondence should be addressed to Hassan Fazaeli, hfazaeli.iust@yahoo.com

Received 13 January 2012; Accepted 20 April 2012

Academic Editor: Pedro Partal López

Copyright () 2012 Hassan Fazaeli et al. This is an open access article distributed under the Creative Commons Attribution License, which permits unrestricted use, distribution, and reproduction in any medium, provided the original work is properly cited.

\begin{abstract}
This paper presents the results of an experimental research on the effects of "Fischer Tropsch-Paraffin" (Sasobit) content on physical and rheological properties of Sasobit modified bitumen at various operational temperatures. For this purpose, bitumen with a Performance Grade (PG) of 58-22 is selected as the base and later it is modified with 1, 2, 2.5, 3, and 4 weight percent of FT-Paraffin (Sasobit). The performance of modified bitumen at high, intermediate, and low temperatures is evaluated based on Strategic Highway Research Program (SHRP) Superpave tests. Results of the study show that FT-paraffin improves the performance of bitumen at high temperatures in addition to increasing the resistance of mixture against permanent deformation. Despite the advantages of FT-paraffin on bitumen performance at high temperatures, it does not show a considerable influence on the intermediate and low temperature performance of bitumen. The effect of FT-paraffin content on the viscosity of modified bitumen is also investigated using Brookfield Viscometer Apparatus. Results show that increasing the additive content lowers the viscosity of modified bitumen. This in return can reduce the mixing and compaction temperature of asphalt mixtures.
\end{abstract}

\section{Introduction}

Flexible pavements are always prone to various distresses during its service life caused by loading- and weatherinduced stresses. High temperature rutting and low temperature cracking are instances of these distresses, the formation of which is known to be highly dependent on performance of the bitumen of the asphalt mixtures [1]. The performance of bitumen at different temperatures can be related to its penetration grade; high penetration grade of bitumen means it is soft, which means higher cracking resistance at low temperatures and higher permanent deformation under loading at high temperatures. On the other hand, bitumen with low penetration grade or hard bitumen has less low temperature cracking but more rutting resistance $[1,2]$. This alteration can be related to the complex rheological behavior of bitumen at different loading times and temperatures $[3,4]$. To improve the behavior of the asphalt mixtures, a well-known solution is to enhance the properties of bitumen. Modification of bitumen using synthetic polymers for improvement of its rheological properties, increasing cohesion and temperature susceptibility, goes back to 1970 s [5-7].

Warm Mix Asphalt (WMA) is an asphalt mixture with lower short-term ageing properties compared to Hot Mix Asphalt (HMA). The reason lies behind the modification of bitumen by additives that reduce the temperature required for asphalt mixture operations such as laying and compaction. This option has some other significant advantages over HMA including less energy consumption for mixture heating and therefore less air pollution of the heating process. According to previous researches, WMA has the following advantages over HMA [8-10].

(i) Reduction of pollutants specially carbon dioxide $\left(\mathrm{CO}_{2}\right)$ up to $30 \%$.

(ii) Reduction of mixing and compaction temperatures of asphalt mixtures in the range of $20^{\circ} \mathrm{C}$ to $40^{\circ} \mathrm{C}$. 
TABle 1: Physical properties of the base bitumen.

\begin{tabular}{lccc}
\hline Test & Method & Unit & Test results \\
\hline Specific Gravity $\left(25^{\circ} \mathrm{C}\right)$ & ASTM D70 & $\mathrm{gr} / \mathrm{cm}^{3}$ & 1.03 \\
Flash Point $($ Cleveland $)$ & ASTM D92 & ${ }^{\circ} \mathrm{C}$ & 308 \\
Penetration $\left(25^{\circ} \mathrm{C}\right)$ & ASTM D5 & $\mathrm{dmm}$ & 62 \\
$\begin{array}{l}\text { Ductility }\left(25^{\circ} \mathrm{C}\right) \\
\text { Softening point }\end{array}$ & ASTM D113 & $\mathrm{cm}$ & 100 \\
Kinematic Viscosity $(v)$ at & ASTM D36 & ${ }^{\circ} \mathrm{C}$ & 49 \\
$120^{\circ} \mathrm{C}$ & ASTM D2170 & $\mathrm{mm}^{2} / \mathrm{s}$ & 810 \\
$\begin{array}{l}\text { Kinematic Viscosity }(v) \text { at } \\
135^{\circ} \mathrm{C}\end{array}$ & ASTM D2170 & $\mathrm{mm}^{2} / \mathrm{s}$ & 420 \\
$\begin{array}{l}\text { Kinematic Viscosity }(v) \text { at } \\
150^{\circ} \mathrm{C}\end{array}$ & ASTM D2170 & $\mathrm{mm}^{2} / \mathrm{s}$ & 232 \\
$\begin{array}{l}\text { Penetration index }(\mathrm{PI}) \\
\text { Penetration Viscosity Number } \\
(\text { PVN })^{\mathrm{b}}\end{array}$ & - & - & -1.12 \\
\hline
\end{tabular}

aPI $=\left[1952-500 \log \left(\mathrm{Pen}_{25}\right)-20 \mathrm{SP}\right] /\left[50 \log \left(\mathrm{Pen}_{25}\right)-\mathrm{SP}-120\right]$.

${ }^{b P V N}=\left[-6.387+1.195 \log \left(\operatorname{Pen}_{25}\right)+1.5 \log \left(\right.\right.$ Visco $\left.\left._{135}\right)\right] /[0.79511-0.1858$ $\left.\log \left(\operatorname{Pen}_{25}\right)\right]$.

(iii) Fuel and energy savings.

(iv) Improvement of compaction operations.

(v) Less delay time for construction operation.

(vi) The possibility for transferring asphalt mixtures to longer distances.

(vii) Easier distribution of asphalt mixtures in cold regions.

(viii) Higher strength against imposed loads.

(ix) Reduction of bitumen ageing.

(x) Improvement of rheological properties of bitumen.

Modification of bitumen is usually carried out by inserting an additive material to the bitumen. For example, commercial waxes are used as flow improver in asphalt concrete and mastic asphalt [1]. There are many forms of waxes such as Synthetic Zeolite (Asphamin), WAM Foam, FT-Paraffin (Sasobit) that can be added to modify the performance of bitumen to apply them in WMA [8-11]. This research is focused on the effects of FT-Paraffin (Sasobit) additive as a commercial wax on the physical and rheological properties of bitumen of WMA.

FT-Paraffin forms a homogeneous solution with the base bitumen in the mixing process and considerably reduces the viscosity of bitumen. After crystallization, FT-Paraffin forms a lattice, reinforcing the structure of bitumen. The recommended percentage of FT-Paraffin is 0.8 to 3 weight percent of the bitumen $[9,10]$.

\section{Experimental Procedures}

\subsection{Materials and Sample Preparation}

2.1.1. Bitumen (Base Bitumen). In order to evaluate the effect of FT-Paraffin content on the performance of asphalt cement,
TABLE 2: Sasobit characteristics.

\begin{tabular}{lcc}
\hline Characteristics & Standard & Value \\
\hline Congealing point & ASTM D938 & $106^{\circ} \mathrm{C}$ \\
Penetration at $25^{\circ} \mathrm{C}$ & ASTM D1321 & $<1 \mathrm{dmm}$ \\
Penetration at $65^{\circ} \mathrm{C}$ & ASTM D1321 & $6 \mathrm{dmm}$ \\
Appearance & - & Prills (diameter $=1 \mathrm{~mm}$ ) \\
\hline
\end{tabular}

60-70 penetration grade bitumen obtained from BandarAbbas Refinery, Iran (with the Performance Grade (PG) of 58-22) is used as base bitumen. Properties of this bitumen are illustrated in Table 1.

2.1.2. FT Paraffin Wax (Sasobit). FT-Paraffin is a long chain aliphatic hydrocarbon (chain lengths are in the range of 40 to 115 carbon atoms), which is obtained from distillation of coal tar using the Fischer-Tropsch process. At temperatures below the melting point, it forms a crystalline network structure in the binder that is reported to provide added stability [12].

The properties of the FT-Paraffin used in this research are shown in Table 2.

2.2. Mixing Procedure. As discussed earlier, FT-Paraffin is added to the base bitumen in amounts of $1,2,2.5,3$, and 4 weight percent of base bitumen at $130^{\circ} \mathrm{C}$. At this temperature, the mixture is stirred for 20 minutes with a frequency of $300 \mathrm{rpm}$ using high shear Silverson model mixer. Physical properties and thermal sensitivity of modified bitumen are determined by the calculation of Penetration Index (PI) and Penetration Viscosity Number (PVN) indices.

\subsection{Test Method}

2.3.1. Conventional Bitumen Tests. Conventional bitumen tests such as softening point (ASTM D36) and penetration grade (ASTM D5) are performed to characterize base bitumen and FT-Paraffin modified bitumen. In addition, to evaluate the effect of FT-Paraffin content on the thermal sensitivity of modified bitumen, the PI and PVN of bitumen are calculated and studied.

The rheological properties of modified bitumen at high and intermediate temperatures are measured by using Dynamic Shear Rheometer (DSR) (ASTM D7175), the creep stiffness of bitumen at low temperatures is measured by using Bending Beam Rheometer (BBR) (ASTM D6648) and the viscosity of the bitumen is evaluated by application of Brookfield rotational viscometer (ASTM D4402).

Finally, by determination of the bitumen performance at various temperatures and classifying them according to Superpave classification system, the performance grades of modified bitumen are determined and compared.

2.3.2. Aging Procedure. Short- and long-term laboratory ageing of the base bitumen and modified bitumen are performed using the Rolling Thin Film Oven (RTFO) test 
TABLE 3: Physical properties of Sasobit modified bitumen.

\begin{tabular}{|c|c|c|c|c|c|c|}
\hline \multirow[b]{2}{*}{ Characteristic } & \multicolumn{6}{|c|}{ Bitumen Type } \\
\hline & PG58-22 & $\begin{array}{l}\text { PG58-22+ } \\
1 \% \text { Sasobit }\end{array}$ & $\begin{array}{l}\text { PG58-22+ } \\
2 \% \text { Sasobit }\end{array}$ & $\begin{array}{c}\text { PG58-22+ } \\
2.5 \% \text { Sasobit }\end{array}$ & $\begin{array}{l}\text { PG58-22+ } \\
3 \% \text { Sasobit }\end{array}$ & $\begin{array}{l}\text { PG58-22+ } \\
4 \% \text { Sasobit }\end{array}$ \\
\hline Penetration $(\mathrm{dmm})$ & 62 & 56 & 51 & 49 & 48 & 42 \\
\hline Softening point $\left({ }^{\circ} \mathrm{C}\right)$ & 49 & 50 & 52 & 57 & 59 & 72 \\
\hline Ductility $(\mathrm{cm})$ & $>100$ & $>100$ & 98 & 95 & 89 & 58 \\
\hline Kinematic viscosity $(v)$ at $135^{\circ} \mathrm{C}$ & 420 & 415 & 408 & 405 & 403 & 379 \\
\hline Penetration index (PI) & -1.12 & -0.94 & -0.64 & 0.65 & 0.73 & 2.7 \\
\hline Penetration viscosity number (PVN) & -0.56 & -0.69 & -0.9 & -0.93 & -0.97 & -1.17 \\
\hline
\end{tabular}

(ASTM D2872) and the pressure ageing vessel (ASTM D6521), respectively.

\subsubsection{Dynamic Shear Rheometer Test (DSR)}

High Temperatures. In this study, Dynamic Shear Rheometer (DSR) is employed on the base bitumen and FT-Paraffin modified bitumen before and after RTFO aging process based on ASTM D7175 using a Bohlin DSR50 rheometer. DSR is performed at high temperatures sweeps (HT) from 46 to $82^{\circ} \mathrm{C}$ at constant frequency of $10 \mathrm{rad} / \mathrm{s}$. The principal viscoelastic parameters which is determined in these temperatures are the complex shear modulus $\left(G^{*}\right)$, phase angle $(\delta)$, storage modulus $\left(G^{\prime}\right)$, and the loss modulus $\left(G^{\prime \prime}\right) . G^{\prime}$ and $G^{\prime \prime}$ are related to each other through the phase angle $(\delta)$, which is the phase shift between the applied shear stress and shear strain responses during the test. The phase angle is a measure of the viscoelastic balance of the material behavior as $\tan \delta=G^{\prime \prime} / G^{\prime}$.

Intermediate Temperatures. The stiffness of bitumen at intermediate temperatures is one of great importance in prevention of fatigue cracks. Using the results of dynamic mechanical analysis, it would be possible to investigate the fatigue behavior of modified bitumen. The fatigue parameter is chosen to reflect the energy dissipated per load cycle, which can be calculated as $G^{*} \cdot \sin \delta$ [13]. The specification prescribed a relationship whereby a reduction in $G^{*} \cdot \sin \delta$ at $1.59 \mathrm{~Hz}$ corresponds to improved fatigue resistance.

In this research, in order to evaluate the effect of FTParaffin content on the bitumen performance at intermediate service temperatures, the DSR test (ASTM D7175) is implemented on the PAV aged bitumen in a temperature range of $19-34^{\circ} \mathrm{C}$ at the constant frequency of $1.59 \mathrm{~Hz}$.

Low Temperatures. To evaluate the effect of FT-Paraffin content on the performance of modified bitumen at low temperatures, the creep stiffness test (ASTM D6648) is implemented by the BBR (Bending beam rheometer) cannon instrument company on base and modified bitumen after the PAV ageing process.

In this study, the beam of bitumen $(127 \mathrm{~mm}$ long, $12.7 \mathrm{~mm}$ wide, and $6.35 \mathrm{~mm}$ thick) is submerged in a constant-temperature bath at each test temperature (starting from $-24^{\circ} \mathrm{C}$ ) for $60 \mathrm{~min}$. After preparing the samples, a $980 \pm 50 \mathrm{mN}$ load is applied for $1 \pm 0.1$ seconds to the rectangular beam, which is supported at both ends by stainless steel half-rounds (102 $\mathrm{mm}$ apart), and the deflection of center point is measured continuously. By implementing this test, the contents of creep rate ( $m$-value), and creep stiffness (St) are determined for all the specimens in -6 to $-24^{\circ} \mathrm{C}$ temperature range at the thermal interval of $6^{\circ} \mathrm{C}$ (ASTM-D6373). The creep rate ( $m$-value) and creep stiffness (St) are also investigated at the specified temperature and various loading times (from 8 seconds to 240 seconds).

\section{Result and Discussion}

3.1. Effect of FT-Paraffin Content on Temperature Susceptibility. The effect of FT-Paraffin content on physical properties of modified bitumen can be seen in Table 3 .

According to Table 3, increasing the content of FTParaffin leads to a decrease in the penetration grade and an increase in softening point of modified bitumen. This trend shows the increased PI index of modified bitumen per increased content of FT-Paraffin, in a way that the modified bitumen containing 4\% FT-Paraffin has the maximum PI index. Moreover, by increasing the content of FT-Paraffin, the bitumen viscosity of bitumen at $135^{\circ} \mathrm{C}$ is decreased. This trend causes a reduction of PVN index. Lower values of PI and PVN indicate higher temperature susceptibility, and asphalt mixtures containing binders with lower temperature susceptibility should be more resistant to cracking and rutting. The reverse trend of PI and PVN shows that the current bitumen tests, which are used as the basis for calculation of thermal sensitivity of bitumen cannot be a suitable criteria for evaluation of the thermal sensitivity of FT-Paraffin modified bitumen.

3.2. Effect of FT-Paraffin Content on Viscosity. The viscosity of bitumen at high temperature is considered as an important factor because it represents the ability to pump bitumen through an asphalt plant, coating aggregate in asphalt concrete mix, and place and compact the mixture [14]. The effect of FT-Paraffin content on the viscosity of the bitumen is evaluated using Brookfield Viscometer (ASTM D7175) at $120^{\circ} \mathrm{C}, 135^{\circ} \mathrm{C}$ and $150^{\circ} \mathrm{C}$ and the viscosity-temperature changes graphs are shown for the base and the FT-Paraffin modified bitumen. 


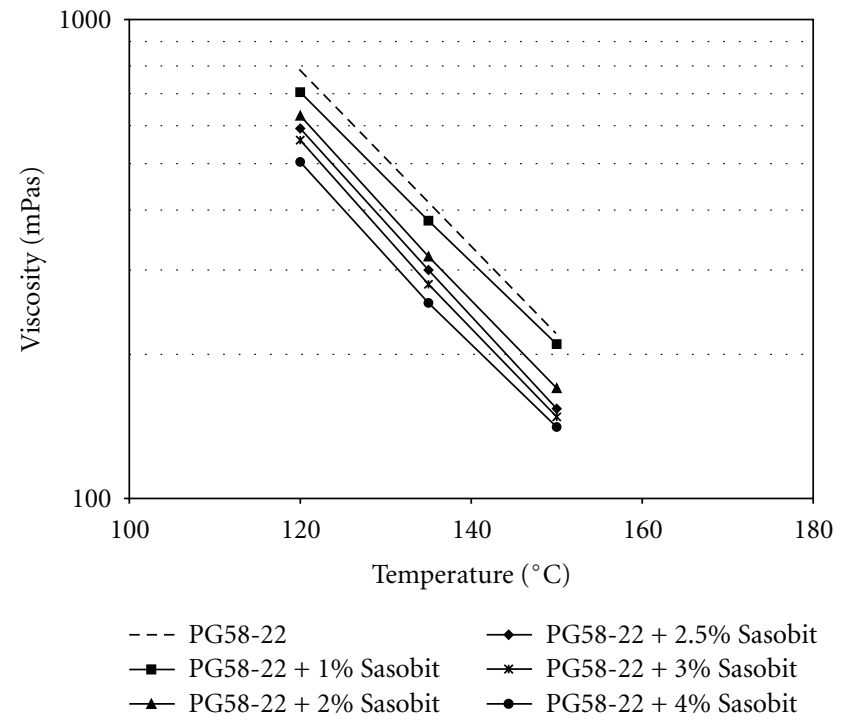

FIGURE 1: Dynamic viscosity curve of Sasobit modified bitumen.

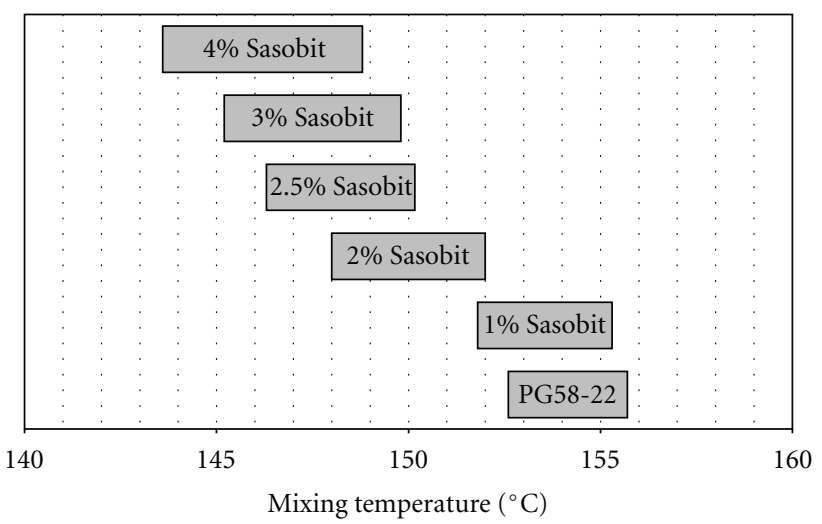

Figure 2: Mixing temperature ranges of Sasobit modified bitumen.

Figure 1 demonstrates that, at a given temperature, by increasing the FT-Paraffin content, the viscosity of bitumen decreases. Figure 1 also shows that the viscosities of all modified bitumen at $135^{\circ} \mathrm{C}$ are less than $3000 \mathrm{mPa} \cdot \mathrm{s}$ and the viscosities of modified bitumen at this temperature, fulfils the ASTM D6373 requirements. The mixing and compaction temperature of the asphalt mixtures have been determined according to the viscosity-temperature graph and this is a temperature at which the bitumen viscosity will be accordingly $170 \pm 20$ and $280 \pm 30$ centistokes (ASTM D6926). From Figure 1, it would be possible to study the effect of FT-Paraffin content on the mixing and compaction temperature of asphalt mixtures. Figures 2 and 3 show the effects of Sasobit content on mixing and compaction temperature ranges, respectively. According to these figures, by increasing the FT-Paraffin content, the mixing and compaction temperatures of asphalt mixture are decreased and therefore, by modification of bitumen by FTParaffin additive, it would be possible to mix and compact asphalt mixtures at lower temperatures.

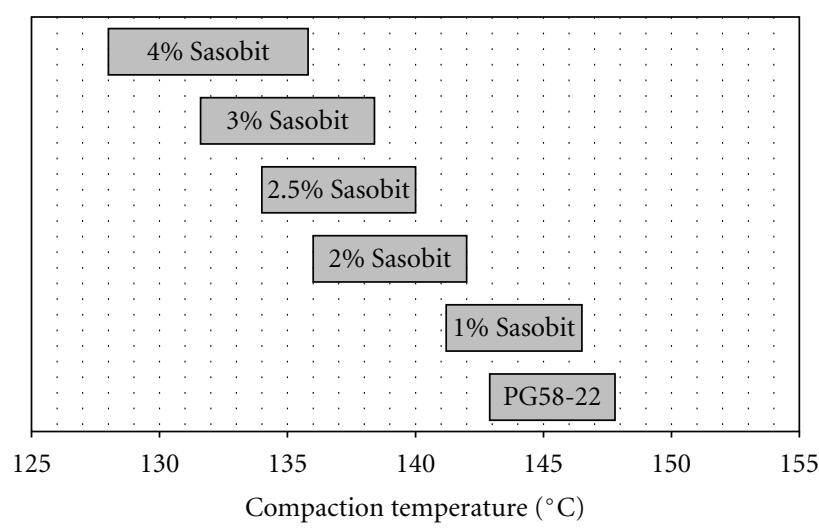

Figure 3: Compaction temperature ranges for Sasobit modified bitumen.

TABLE 4: Effects of Sasobit additives on high service temperatures.

\begin{tabular}{lcc}
\hline Sample code & HT $\left({ }^{\circ} \mathrm{C}\right)$ & HT variation $\left({ }^{\circ} \mathrm{C}\right)$ \\
\hline PG58-22 & 62.5 & - \\
PG58-22 + 1\% Sasobit & 67.5 & +5.0 \\
PG58-22 + 2\% Sasobit & 69.2 & +6.7 \\
PG58-22 + 2.5\% Sasobit & 70.8 & +8.3 \\
PG58-22 + 3\% Sasobit & 71.7 & +9.2 \\
PG58-22 + 4\% Sasobit & 74.2 & +11.7 \\
\hline
\end{tabular}

3.3. The Performance of FT-Paraffin-Modified Bitumen at High Temperatures. For rutting resistance, a high complex modulus $\left(G^{*}\right)$ value is favorable because it represents a higher total resistance to deformation and a lower phase angle $(\delta)$ is favorable as well because it reflects a more elastic (recoverable) component of the total deformation. According to this study, at a given temperature, by increasing the FT-Paraffin additive in base bitumen, the $G^{*}$ and $\delta$ values have increased and decreased, respectively. A similar trend can be seen for modified bitumen after the RTFO ageing process.

In the Superpave binder specification, rutting is taken into account using a rutting factor $\left(G^{*} / \sin \delta\right)$, which is solely dependent on the rheological properties of the asphalt binder. The higher the rut factor for the binder, the stiffer the asphalt concrete should be and thus more resistant to rutting.

Figures 4 and 5 show the $G^{*} / \sin \delta$ trend for base and modified bitumen, before and after the RTFO ageing process in a temperature range of $46^{\circ} \mathrm{C}$ to $82^{\circ} \mathrm{C}$ and at the constant frequency of $1.59 \mathrm{~Hz}$. The simultaneous increase of $G^{*}$ and reduction of $\delta$ with the increased content of FT-Paraffin increases the rut factor $\left(G^{*} / \sin \delta\right)$ as well as the resistance against permanent deformation at high temperatures.

Table 4 shows the effects of FT-Paraffin content on the high service temperature. The high service temperature is a temperature at which the $G^{*} / \sin \delta$ will be larger than $1 \mathrm{kPa}$ $\left(G^{*} / \sin \delta>1 \mathrm{kPa}\right)$ for unaged bitumen and larger than $2.2 \mathrm{kPa}\left(G^{*} / \sin \delta>2.2 \mathrm{kPa}\right)$ for RTFO aged bitumen (ASTM D2872). 


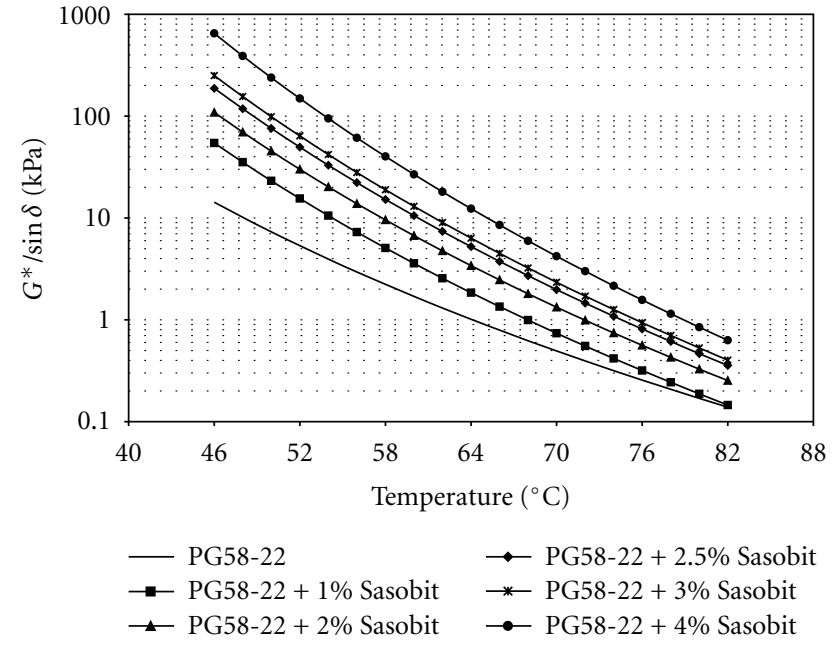

Figure 4: $G^{*} / \sin \delta$ as a function of temperature at $1.59 \mathrm{~Hz}$ for unaged bitumen.

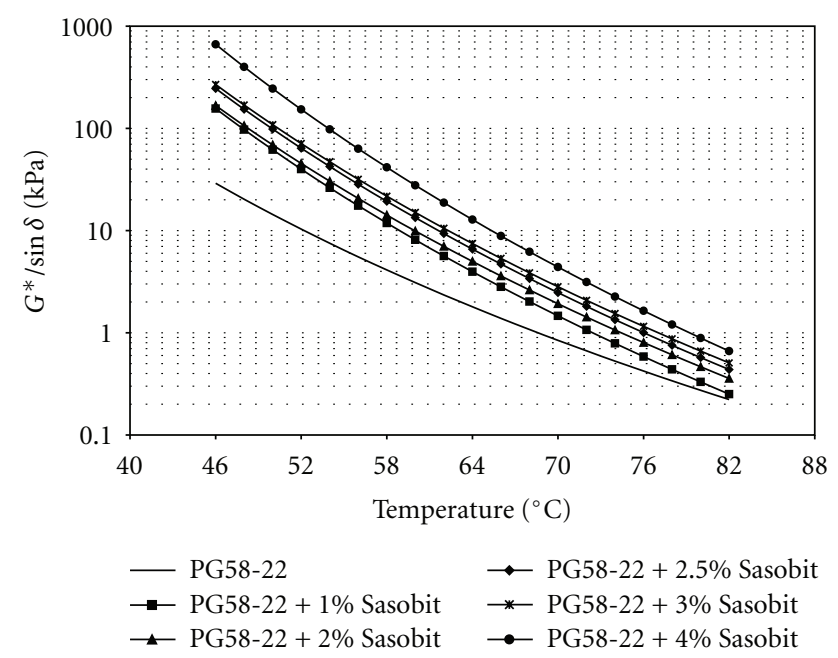

Figure 5: $G^{*} / \sin \delta$ as a function of temperature at $1.59 \mathrm{~Hz}$ for RTFO aged bitumen.

According to Table 4, the maximum pavement design temperature increases with the increase in FT-Paraffin content. This trend improves the bitumen performance at high temperatures. Figure 6 is the graph of $\tan \delta$ for temperature range $42^{\circ} \mathrm{C}-82^{\circ} \mathrm{C}$ at the constant frequency of $1.59 \mathrm{~Hz}$. This graph has been used to study the viscoelastic behavior of modified bitumen and evaluate their elasticity sensitivity at various temperatures. This figure shows that the value of $\tan \delta$ decreases with the increase in FT-Paraffin content at this temperature range, in a way that the bitumen samples containing more contents of FT-Paraffin have less sensitivity against thermal changes in comparison with samples containing no or less additive. On the other hand, bitumen samples containing higher FT-Paraffin content, the viscoelasticity of bitumen is less dependent to thermal changes.

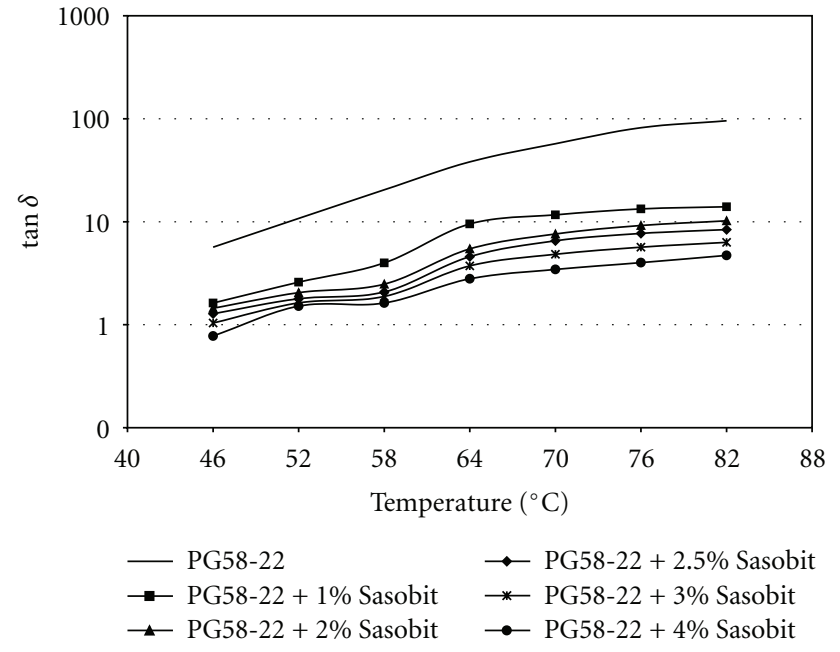

Figure 6: $\tan \delta$ as a function of temperature at $1.59 \mathrm{~Hz}$ for unaged bitumen.

TABLE 5: Effects of FT-Paraffin additive on intermediate service temperatures.

\begin{tabular}{lcc}
\hline Sample code & IT $\left({ }^{\circ} \mathrm{C}\right)$ & IT variation $\left({ }^{\circ} \mathrm{C}\right)$ \\
\hline PG58-22 & 21.6 & - \\
PG58-22 + 1\% Sasobit & 23.6 & -2.0 \\
PG58-22 + 2\% Sasobit & 24.7 & -3.1 \\
PG58-22 + 2.5\% Sasobit & 25.8 & -4.2 \\
PG58-22 + 3\% Sasobit & 26.4 & -4.8 \\
PG58-22 + 4\% Sasobit & 27.5 & -5.9 \\
\hline
\end{tabular}

3.4. The Performance of FT-Paraffin-Modified Bitumen at Intermediate Temperatures. The intermediate service temperature $(\mathrm{IT}=(\mathrm{HT}+\mathrm{LT}) / 2+4)$ is a temperature at which the $G^{*} \cdot \sin \delta$ for PAV aged bitumen (ASTM D2872) becomes less than $5000 \mathrm{kPa}$. Figure 7 shows the effect of FT-Paraffin content on the values of $G^{*} \cdot \sin \delta$ for PAV aged binders. It can be seen that increasing the content of FT-Paraffin in base bitumen causes increase in the values of $G^{*} \cdot \sin \delta$. This trend has an undesirable effect on the performance of bitumen at intermediate temperatures. Although the PG5822 bitumen fulfills the above-mentioned requirement for intermediate temperature at $21.6^{\circ} \mathrm{C}$, bitumen containing contents of FT-Paraffin are able to fulfill the requirements at higher temperatures. Therefore, it can be stated that the modification of bitumen by FT-Paraffin additive does not have a remarkable effect on fatigue resistance of the asphalt mixture.

The increased amount of intermediate service temperature (IT) per various amounts of FT-Paraffin additive has been represented in Table 5 .

3.5. The Performance of FT-Paraffin-Modified Bitumen at Low Temperatures. In pavement design, low temperature is the temperature at which the PAV aged bitumen beam has creep stiffness of $300 \mathrm{MPa}$ minus $10^{\circ} \mathrm{C}, 60$ seconds after loading 


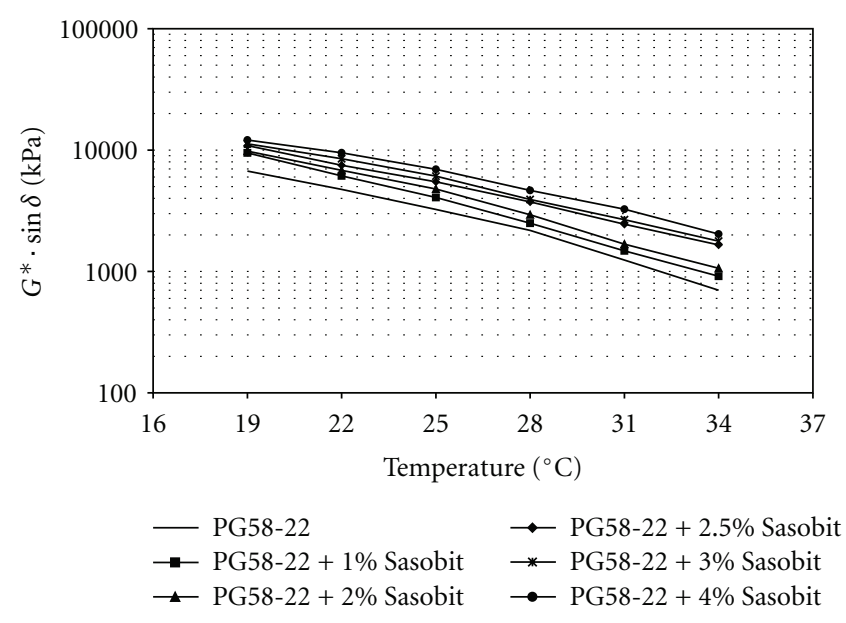

Figure 7: $G^{*} \cdot \sin \delta$ versus temperature at $1.59 \mathrm{~Hz}$ for PAV aged bitumen.

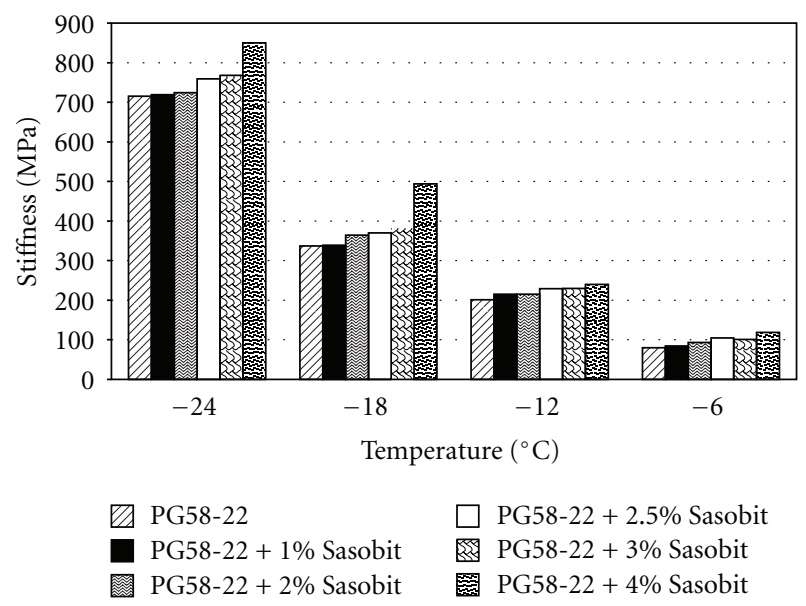

Figure 8: Stiffness of Sasobit-modified bitumen at different temperatures.

by bending beam rheometer apparatus. The $m$-value of the bitumen beam is more than 0.3 at the time of loading.

Figure 8 shows the stiffness of Sasobit modified bitumen at different temperatures. From this figure, it can be observed that when FT-Paraffin content increases, the stiffness of bitumen at low temperature is also increased. This trend is more apparent at lower temperatures. Figure 9 shows the $m$-value change tendency with temperature for base and modified bitumen. According to this figure, at a given temperature, higher FT-Paraffin content result in lower $m$-value. The variation of stiffness and $m$-values shows that increasing FTParaffin percentage exacerbates the performance of modified bitumen at low temperatures. In other words, specimens containing lower contents of this additive will have better performance at low temperature. It must be noted that although higher FT-Paraffin content reduces the minimum pavement design temperature, the trend is in such a way that even in the worst situations (4\% FT-Paraffin) the lower limit of performance grade remains unchanged.

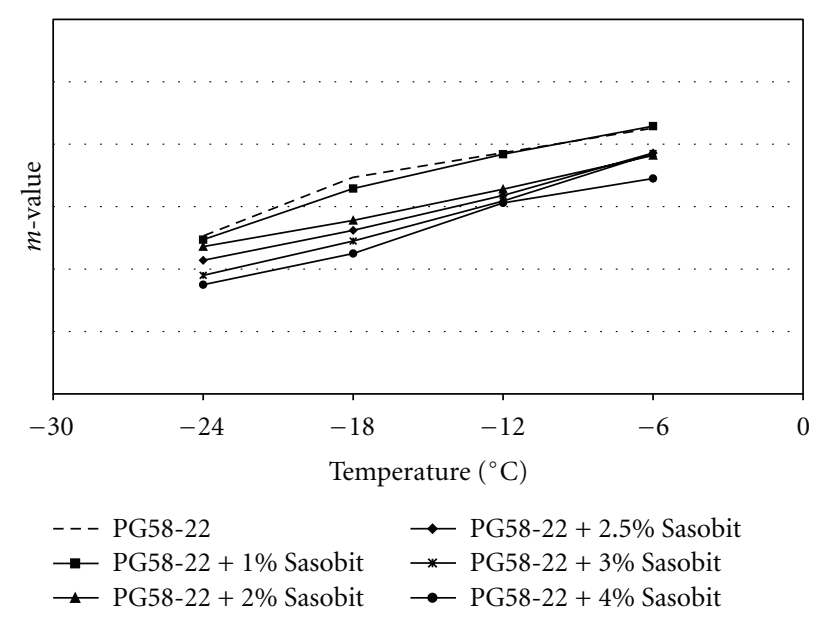

Figure 9: $m$-values of Sasobit modified bitumen at different temperatures.

TABLE 6: Effects of Sasobit additives on low service temperatures.

\begin{tabular}{lcc}
\hline Sample code & LT $\left({ }^{\circ} \mathrm{C}\right)$ & LT variation $\left({ }^{\circ} \mathrm{C}\right)$ \\
\hline PG58-22 & -16.4 & - \\
PG58-22 + 1\% Sasobit & -16.1 & -0.3 \\
PG58-22 + 2\% Sasobit & -14.7 & -1.7 \\
PG58-22 + 2.5\% Sasobit & -13.9 & -2.5 \\
PG58-22 + 3\% Sasobit & -11.3 & -5.1 \\
PG58-22 + 4\% Sasobit & -10.6 & -5.8 \\
\hline
\end{tabular}

The minimum temperature value at which the bitumen meets the requirements is represented in Table 6; this temperature is called low service temperature (LT). From the table, it can be vividly seen that higher contents of FTParaffin cause a rise in minimum design temperature of pavements.

3.6. Effect of FT-Paraffin on SHRP Performance Grade. Figure 10 shows the changes of performance grade (PG) of base and FT-Paraffin modified bitumen on the basis of Superpave performance classification system (ASTM D6373). According to this figure, by increasing the FTParaffin content, the performance of modified bitumen samples shows considerable improvement at high temperature, in such a way that the upper limit of bitumen's performance grade has ascended from 58 to 70 for the FT-Paraffin modified bitumen containing 4\% FT-Paraffin. In spite of the positive effect of FT-Paraffin additive on the improvement of performance grade at high temperatures, this material identifies no sign of upgrade on low temperatures performance with the application of the additive. The lower limit of bitumen performance grade for all FT-Paraffin contents are determined to be $-22^{\circ} \mathrm{C}$, similar to that of the base bitumen. 


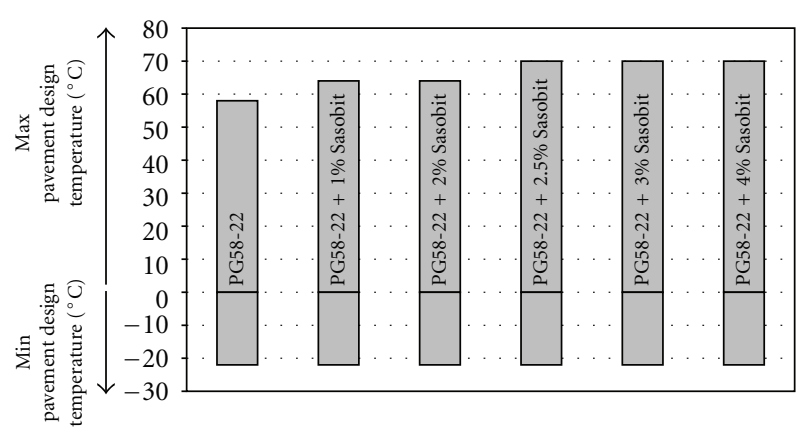

Figure 10: Performance grade of Sasobit modified bitumen.

\section{Conclusion}

This research evaluates the effects of FT-Paraffin (Sasobit) content on the performance of PG58-22 base bitumen with the following conclusions.

(i) The test results show that the increase in FT-Paraffin content results in higher stiffness and lower softening point. An adverse effect of additive on PI versus PVN shows that the current tests are not appropriate criteria for evaluating the effects of Sasobit content on thermal sensitivity of modified bitumen.

(ii) Higher Sasobit content leads to higher $G^{*}$ and lower $\delta$ and consequently higher $G^{*} / \sin \delta$ (rutting factor) before and after RTFO ageing process. The increase of $G^{*} / \sin \delta$ means an improvement on the performance of modified bitumen against permanent deformation at high temperature.

(iii) When the additive content is increased, the $G^{*} \cdot \sin \delta$ value is also increased which may mean an aggravation in the performance of bitumen at intermediate temperature. This may be followed by the reduced strength of asphalt mixtures against fatigue cracking.

(iv) At any given temperature of the study range, increasing Sasobit content leads to an increase in bitumen stiffness at low temperature and a decrease in the $m$-value which means higher minimum pavement design temperature.

(v) Adding FT-Paraffin (Sasobit) to bitumen results in lower bitumen viscosity. Increasing Sasobit percentage reduces the mixing and compaction temperature range of asphalt mixtures and these processes can be carried out at lower temperatures.

(vi) With higher amounts of Sasobit, the upper level of bitumen performance grade at high temperature improves considerably. Despite the positive effect of Sasobit on the high temperature performance, this material shows no positive effect on low temperature performance of PG58-22 bitumen.

\section{Acknowledgment}

The authors would like to thank Behin Taraddod Iranian Corporation for supplying the required materials and their financial supports.

\section{References}

[1] Y. Tasdemir, "High temperature properties of wax modified binders and asphalt mixtures," Construction and Building Materials, vol. 23, no. 10, pp. 3220-3224, 2009.

[2] B. Zhang, M. Xi, D. Zhang, H. Zhang, and B. Zhang, "The effect of styrene-butadiene-rubber/montmorillonite modification on the characteristics and properties of asphalt," Construction and Building Materials, vol. 23, no. 10, pp. 31123117, 2009.

[3] G. D. Airey, "Styrene butadiene styrene polymer modification of road bitumens," Journal of Materials Science, vol. 39, no. 3, pp. 951-959, 2004.

[4] U. Isacsson and X. Lu, "Characterization of bitumens modified with SEBS, EVA and EBA polymers," Journal of Materials Science, vol. 34, no. 15, pp. 3737-3745, 1999.

[5] B. Brulz, Y. Brion, and A. Tanguy, "Paving asphalt polymer blends relationship between composition, structure and properties," in Proceedings of the Association of Asphalt Paving Technologists, vol. 57, pp. 41-64, 1988.

[6] J. H. Collins, M. G. Bouldin, R. Gelles, and A. Berker, "Improved performance of paving asphalts by polymer modification," in Proceedings of the Association of Asphalt Paving Technologists, vol. 60, pp. 43-79, March 1991.

[7] J. L. Goodrich, "Asphaltic binder rheology, asphalt concrete rheology and asphalt concrete mix properties," in Proceedings of the Association of Asphalt Paving Technologists, vol. 60, pp. 80-120, March 1991.

[8] J. D’Angelo, E. Harm, J. Bartoszek et al., "Warm mix asphalt: European practice," Federal Highway Administration Reports FHWA-PL-08-007, 2007.

[9] G. Hurley and B. Prowell, "Evaluation of Evotherm for use in warm mix asphalt," National Center for Asphalt Technology (NCAT) Reports 06-02, National Center for Asphalt Technology, Auburn, Ala, USA, 2006.

[10] G. Hurley and B. Prowell, "Evaluation of Sasobit for use in warm mix asphalt," NCAT Report 05-06, National Center for Asphalt Technology, Auburn, Ala, USA, 2005.

[11] W. Barthell, J. P. Marchand, and D. M. Von, "Warm asphalt mixes by adding a synthetic zeolite," in Proceedings of the 3rd Eurasphalt and Eurobitume Conference, vol. 1, pp. 1241-1249, 2004.

[12] S.-J. Lee, S. N. Amirkhanian, N.-W. Park, and K. W. Kim, "Characterization of warm mix asphalt binders containing artificially long-term aged binders," Construction and Building Materials, vol. 23, no. 6, pp. 2371-2379, 2009.

[13] D. A. Anderson and T W. Kennedy, "Development of SHRP binder specification," in Proceedings of the Association of Asphalt Paving Technologists, vol. 62, pp. 481-507, 1993.

[14] R. Burger, M. F. C. Van de Ven, J. Muller, and K. L. Jenkins, "Rheology of polymer modified bitumen a comparative study of three binders and three binder/filler systems," in Proceedings of the 20th South African Transport Challenge Conference, 2001. 

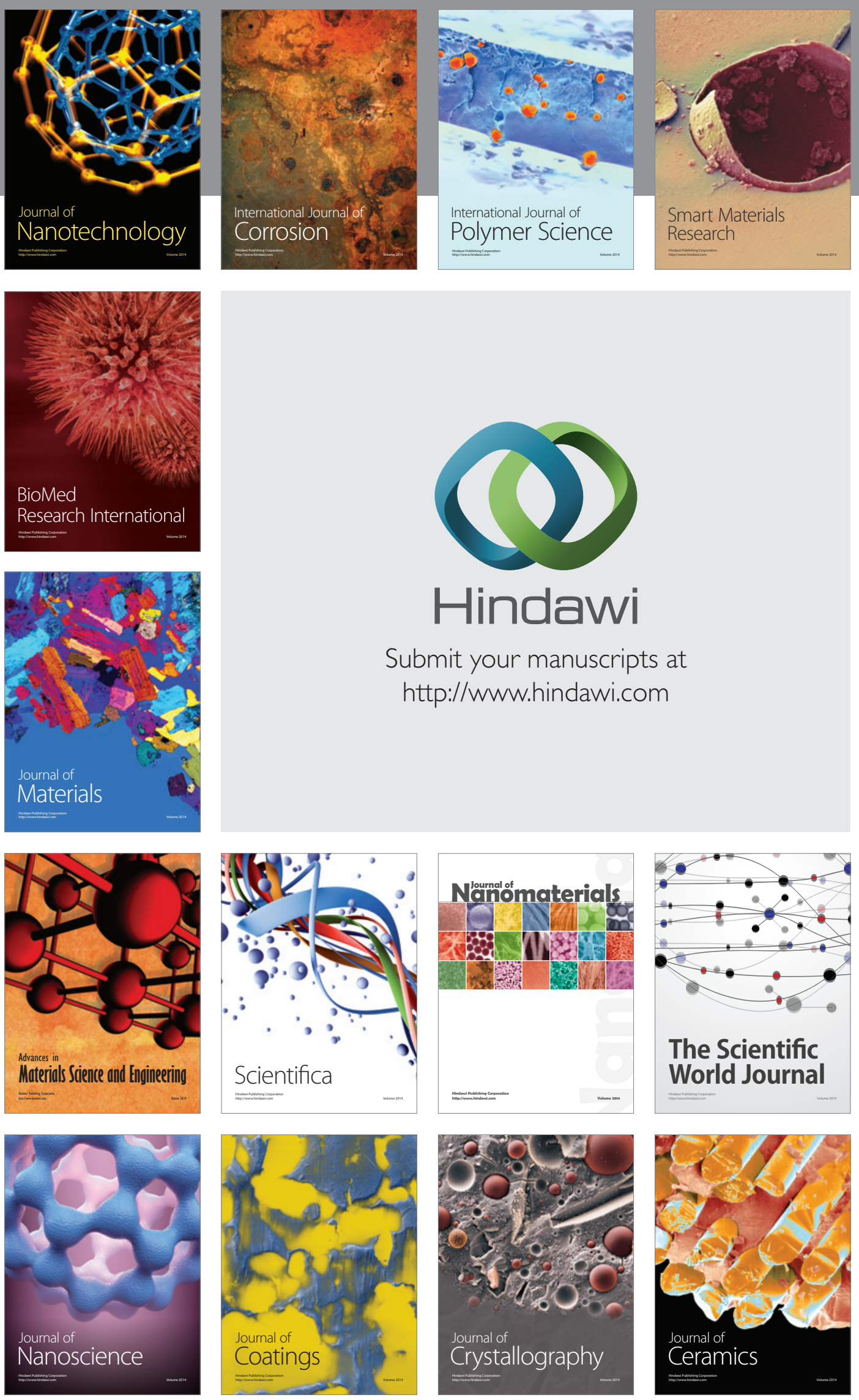

The Scientific World Journal

Submit your manuscripts at

http://www.hindawi.com

\section{World Journal}

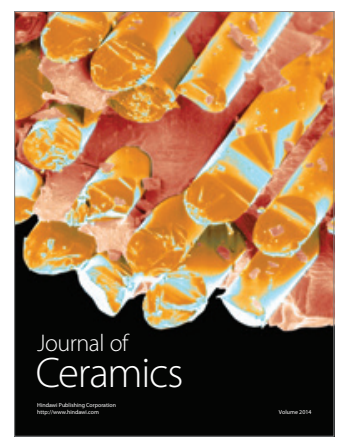

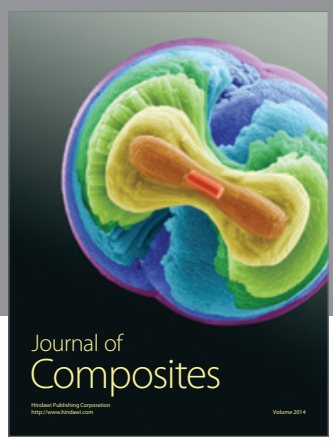
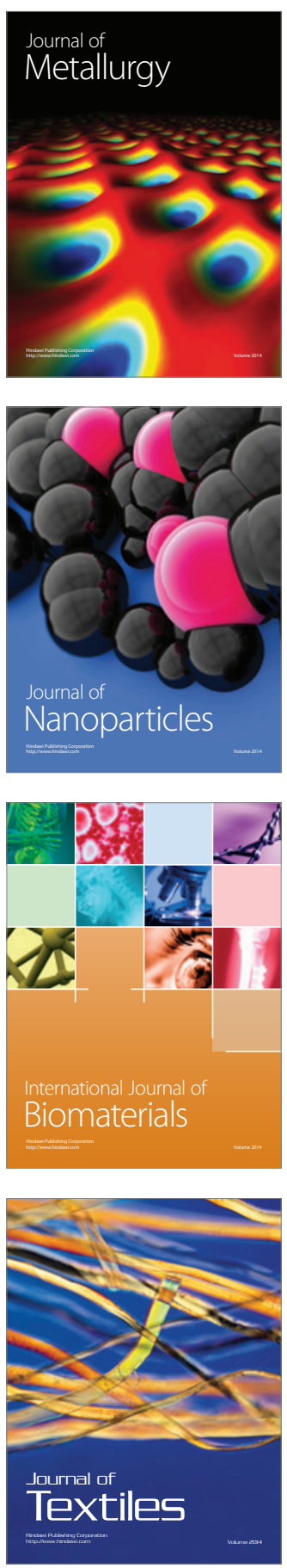